\title{
The Effect of Denture Base Repair with Special Type of Acrylic O-Cry1 and Different Surface Treatments on Impact Bond Strength of Acrylic Resin (Comparative Study)
}

\author{
Alaa Ezat abdulalmajeed \\ Lecturer - B.D.T , Msc Dental technology - Prosthodontic department - College of Health \& Medical Technology /Baghdad \\ Middle Technical University
}

\begin{abstract}
Background: the common problem in prosthodontics is a fracture of the denture base and it represents an annoyance for the dentists. Therefore, the option of increasing repair strength using new reinforcement materials is of great interest to prosthodontists. The purpose of this study was to assess the effects of using a special type of acrylic o-cry1 in repair instead of heat cure acrylic resins and different surface treatments on impact bond strength using Ivomet and conventional curing methods.

Materials and Methods: One hundred thirty specimens of heat acrylic resins were constructed. There are 2 main groups according to curing methods (Ivomet and conventional method curing). For each group, there were 6 groups according to the surface treatments used (untreated, monomer, thiner, zirconium oxide, glass fiber and butt joint with monomer) as well as control group. Results: The study showed that the control group had a higher value of impact strength than other groups which were cured by conventional method. For Ivomet curing, the butt joint with monomer and glass fiber groups improved the impact bond strength in comparison to other groups.

Conclusion: the butt joint with monomer treatment and glass fiber groups have improved the impact strength of the repaired acrylic resins when using Ivomet compared with other groups. On the other hand, the use of thiner and zirconium oxide reduced the impact bond strength when using the conventional curing method. The use of Ivomet device in curing samples improved the impact strength of acrylic repaired with O-cry1.
\end{abstract}

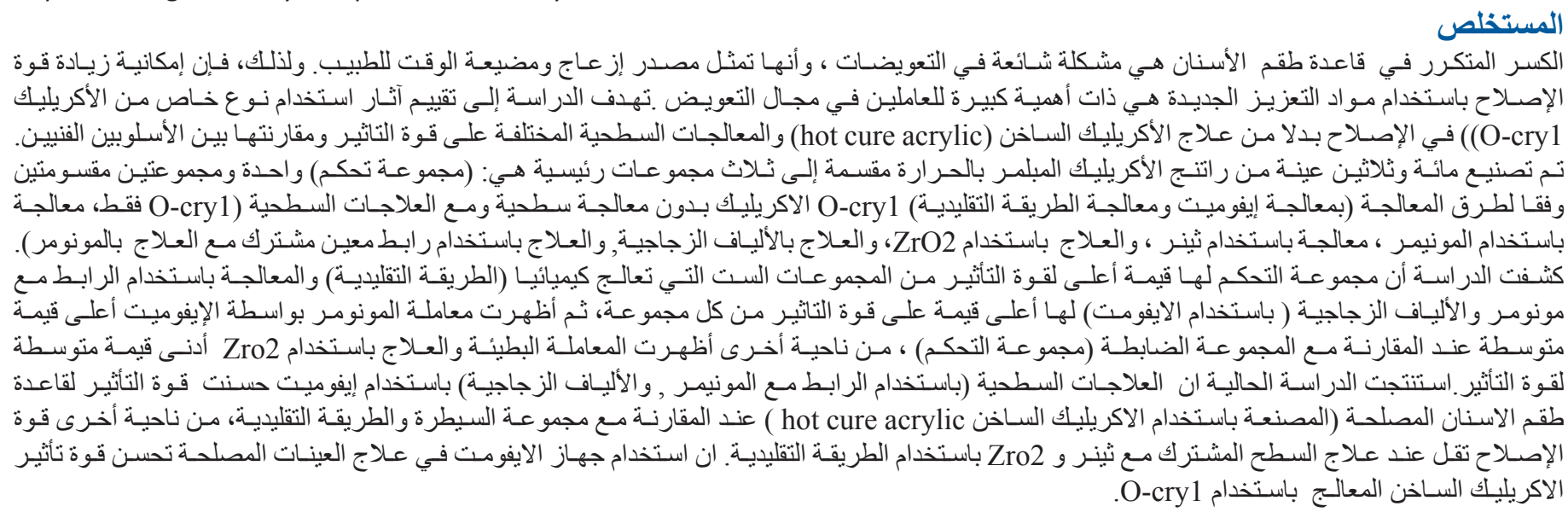

\section{INTRODUCTION}

In dentistry, acrylic resins are widely used for fabrication of removable dentures. Such materials may be fractured when dropping. The construction of a new removable denture is time consuming and very expensive for the patients. Hence, the repair of such dentures is preferred for both dentists and patients $(1,2)$. The type of material used, surface design, surface treatment and material reinforcement are the main factors, which affect the success of denture repair ${ }^{(3)}$. The procedure of repairing dentures includes the use of repair material to join two or more fractured pieces (4). Auto-cured, heat cured and light or microwave acrylic resin have been used to repair the fractured denture ${ }^{(5-6)}$. The success of denture repair depended on adhesion between fractured pieced and repair material (7). Surface preparation of the sites to be joined is of paramount importance in ensuring along service life. Chemical or mechanical treatments could change the morphology or surface chemistry of the acrylic resin base material to promote better adhesion ${ }^{(1)}$. Different chemical solvents such as acetone, monomer and thiner have been used to repair of light-cured acrylic resins $^{(8)}$. Zirconia (ZrO2) is a metal oxide and may be used to enhance the flexural strength of acrylic resin ${ }^{(9-11)}$. The adding of glass fiber to repair material improves the strength of a denture base repair and may decrease the occurrence of future fracture ${ }^{12-}$ 14). The aim of the study was to assess the impact of using O-cry1 in repair without surface treatments and with surface treatments on impact bond strength of repaired acrylic specimens using two curing methods.

\section{MATERIAL AND METHODS \\ Grouping of specimens}

In total, 130 rectangular samples of heat cured resin with dimensions ( $80 \mathrm{mmx} 10 \mathrm{mmx} 4 \mathrm{~mm}$ ) length, width, and thickness respectively were prepared and divided according to the surface treatments and methods of activation. There were three main groups; 
The first group (10 specimens) were prepared for control group (repaired with heat cure acrylic and cured by Ivomet). The second group (60 specimens) which were cured by conventional method and involved 6 groups with each group had 10 samples depending on the type of surface treatment used (untreated, monomer, thiner, zirconium oxide filler, butt joint and monomer, glass fibers). The third group (60 specimens) were cured by Ivomet and consisted of 6 groups as the second group.

\section{Preparation of acrylic specimens}

\section{Plastic pattern preparation}

A wax pattern was constructed with a dimension of $(80 \mathrm{~mm} \times 10 \mathrm{~mm} \times 4 \mathrm{~mm})$ length, width and thickness respectively for impact strength test according to ISO $179,2000^{(15)}$ used to fabricate acrylic specimens for the impact test (Figure 1).

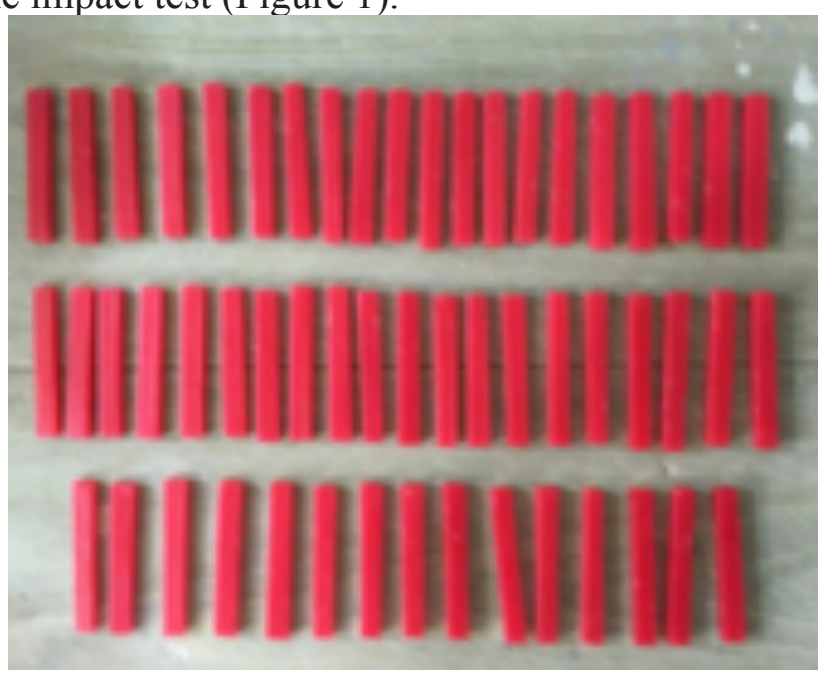

Figure 1. Wax pattern

\section{Investing procedure}

A lower part of the flask was coated with a Vaseline. According to manufacturer instructions (the ratio of powder to water was $100 \mathrm{~g} / 25 \mathrm{ml}$ ), the mixed dental stone was placed into lower part and the wax pattern was placed in the stone mixture ${ }^{(16)}$. After final set of dental stone, the surface of the stone was coated with separating medium and left to dry (figure 2). The upper half of the flask was painted with separating medium, then mounted on the top of the lower portion. Under vibration the upper half of the flask was filled with freshly mixed stone. The dental stone was allowed to set for one hour. After final set of dental stone, the boil out procedure was carried out for 5 minutes to eliminate the wax pattern. The upper and lower halves were separated and a detergent was used to eliminate the wax residua to leaving spaces to be occupied by acrylic materials.

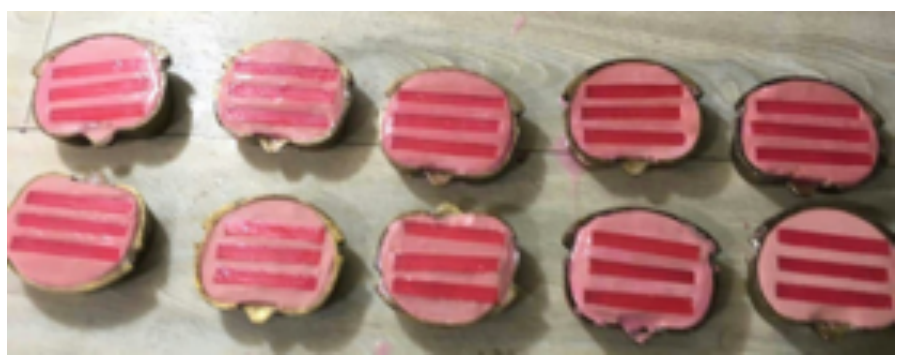

Figure 2. Specimens positioned within the mould

3. Proportioning and mixing of the acrylic

The acrylic resin was manipulated and mixed according to manufacture instructions. Packing process was then performed while the acrylic was in the dough stage, as recommended by ADA Specification No.12, $1999^{(17)}$. The 2 parts of flask were put in contact under hydraulic press. The flask was then mounted onto clamp; transferred to water bath for curing. After completing the curing, the flask was allowed to cool at room temperature before deflasking. The acrylic samples were then removed from the stone mould. All the specimens were carefully removed from the mould after deflasking and were finished and polished ${ }^{(17)}$. All the specimens were stored in distilled water at $37 \mathrm{C}$ for 48 hours, before fracture ${ }^{(17-18)}$.

\section{Repair procedure}

The samples were fractured by using a metal holding device. Each sample was positioned in a central groove, and cut with a fissure bur (figure 3). The space of $3 \mathrm{~mm}$ was created between two halves as demonstrated in the figure $4^{(19-20)}$.

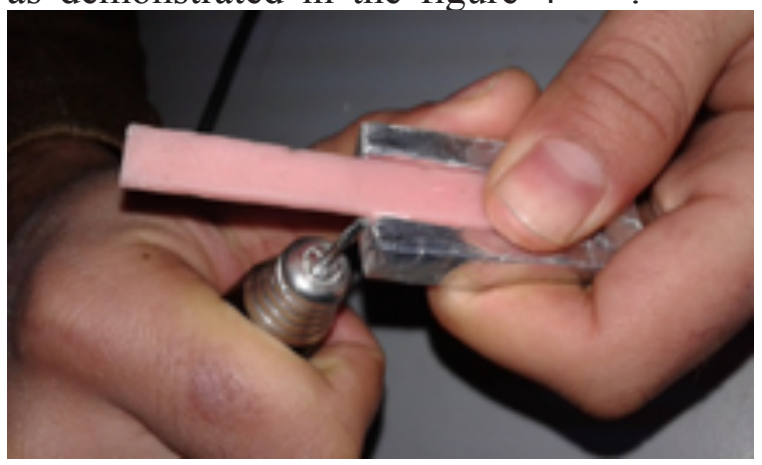

Figure 3: Fracture of the specimens

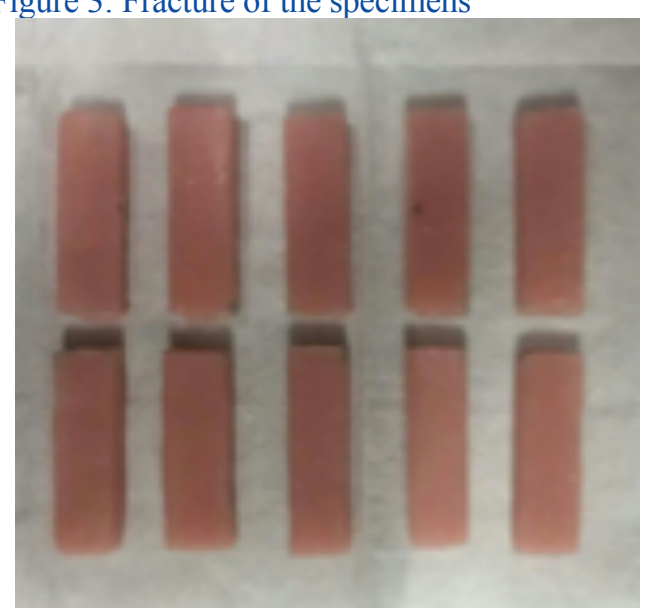

Figure 4: Specimens after the fracture 
The control group was repaired with heat cured resin a using pressure pot (Ivomet) for 30 minutes at $40^{\circ} \mathrm{C}^{(21)}$. Similar steps of finishing and polishing of acrylic specimens were followed for repairing specimens. Acrylic samples were then stored in the distilled water at $37{ }^{\circ} \mathrm{C}$ for 48 hours before testing. Samples repaired using conventional method

The untreated group was repaired with $\mathrm{O}$ cryl without any surface treatments. The thiner group was repaired with using a thiner (Iraq) with $\mathrm{O}$ acry $1^{(8)}$.
The butt joint with monomer group was repaired by placement the pieces from stainless steel in the gap and painted with a monomer for 180 seconds before repairing with $\mathrm{O}$ cry (figure 4$)^{(22)}$. The glass fiber group was repaired using a glass fiber (china), with $\mathrm{O}_{-}$ cryl(figure 5) ${ }^{(22)}$. The monomer group was repaired with monomer for three minutes ${ }^{(1)}$. Zirconium oxide ( $\mathrm{ZrO} 2)$ group was repaired by the addition of $\mathrm{ZrO} 2$ filler concentration of $3 \%(0.3 \mathrm{~g})$ to the powder $(9.7$ g) and mixed with monomer $(4.4 \mathrm{ml}){ }^{(23,11)}$.

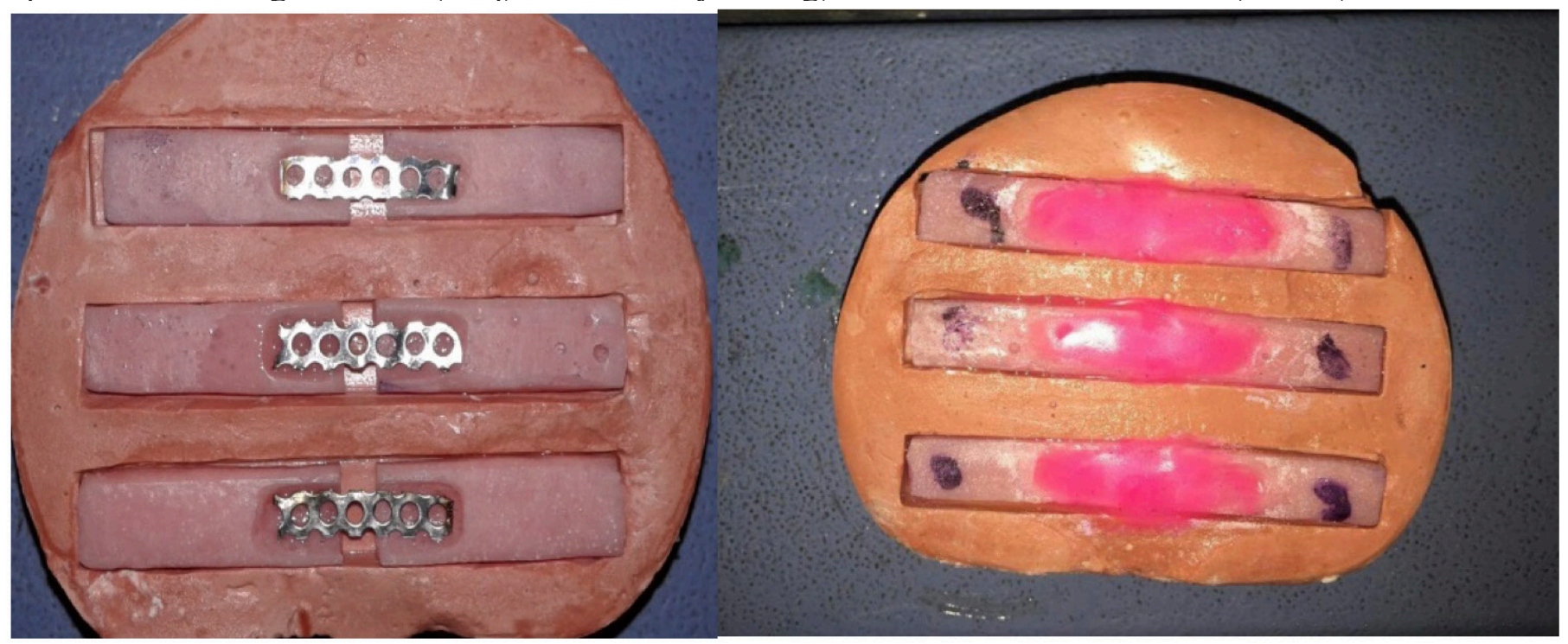

Figure 4. Specimens repaired by butt joint treatment

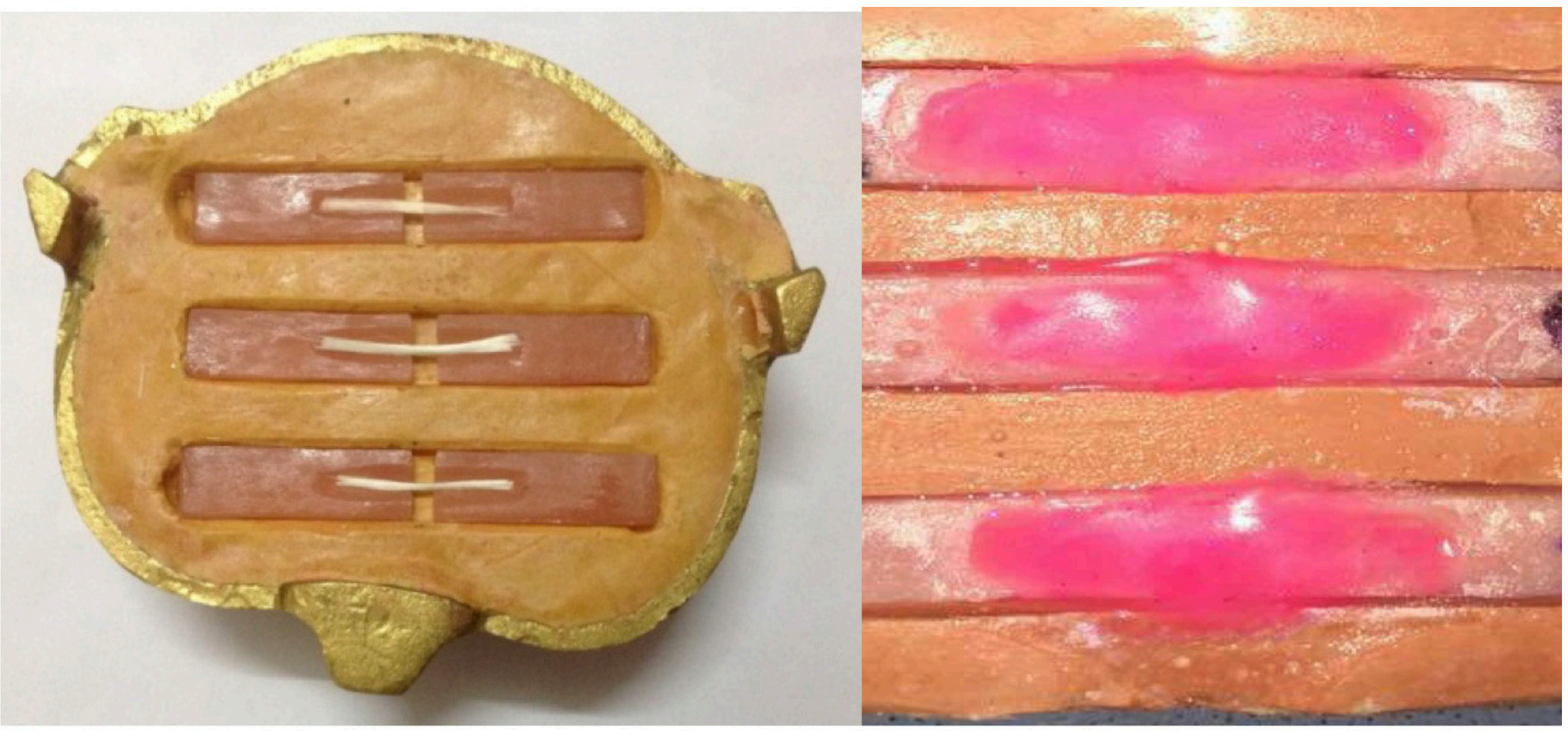

Figure5. Specimens repaired with glass fiber treatment

Similar steps of finishing and polishing of acrylic specimens were followed for repaired specimens. The samples were kept in distilled water for 48 hours.

\section{Acrylic samples repaired with Ivomet}

Similar steps were conducted for repairing acrylic samples, which were cured by Ivomet (figure 6) ${ }^{(19)}$. Similar steps of finishing and polishing of acrylic specimens were followed for repaired specimens. The repaired specimens were stored in the distilled water at $37^{\circ} \mathrm{C}$ for 48 hours before testing. 


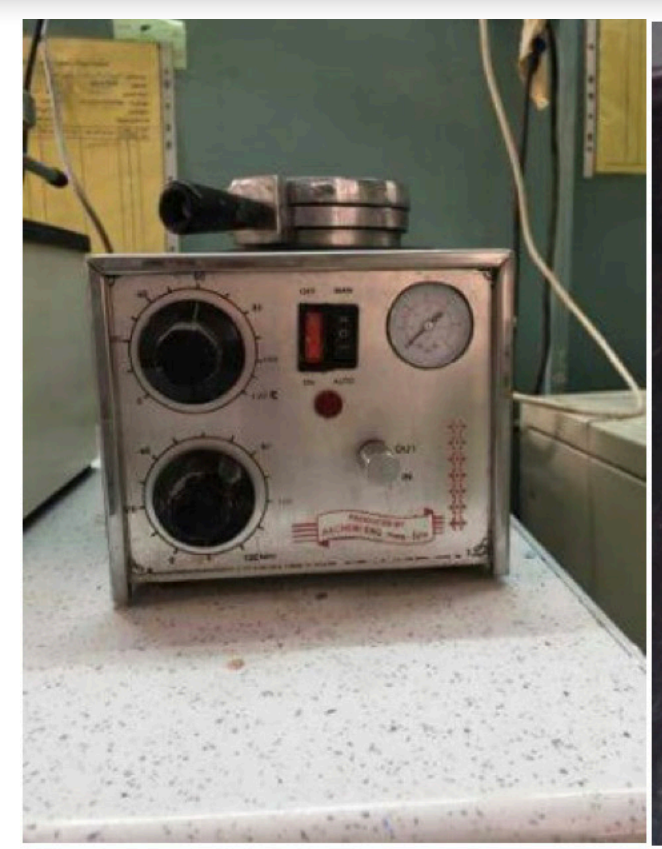

Figure 6. Ivomet device and curing procedure

\section{Impact strength test}

The impact strength test was performed according to IS 179 with impact testing device (figure7). All specimens were supported horizontally at each end and struck by free swinging pendulum of two joules. The impact strength values were calculated in kilojoules per square meter $(\mathrm{KJ} / \mathrm{M} 2)$ using the following formula:

Impact strength $=\mathrm{E} / \mathrm{B} \mathrm{D} \times 10$ (ISO, 2000) where $\mathrm{E}$ : is the impact absorbed energy in joules. B represents width of the specimens. D represents the thickness of the specimens.

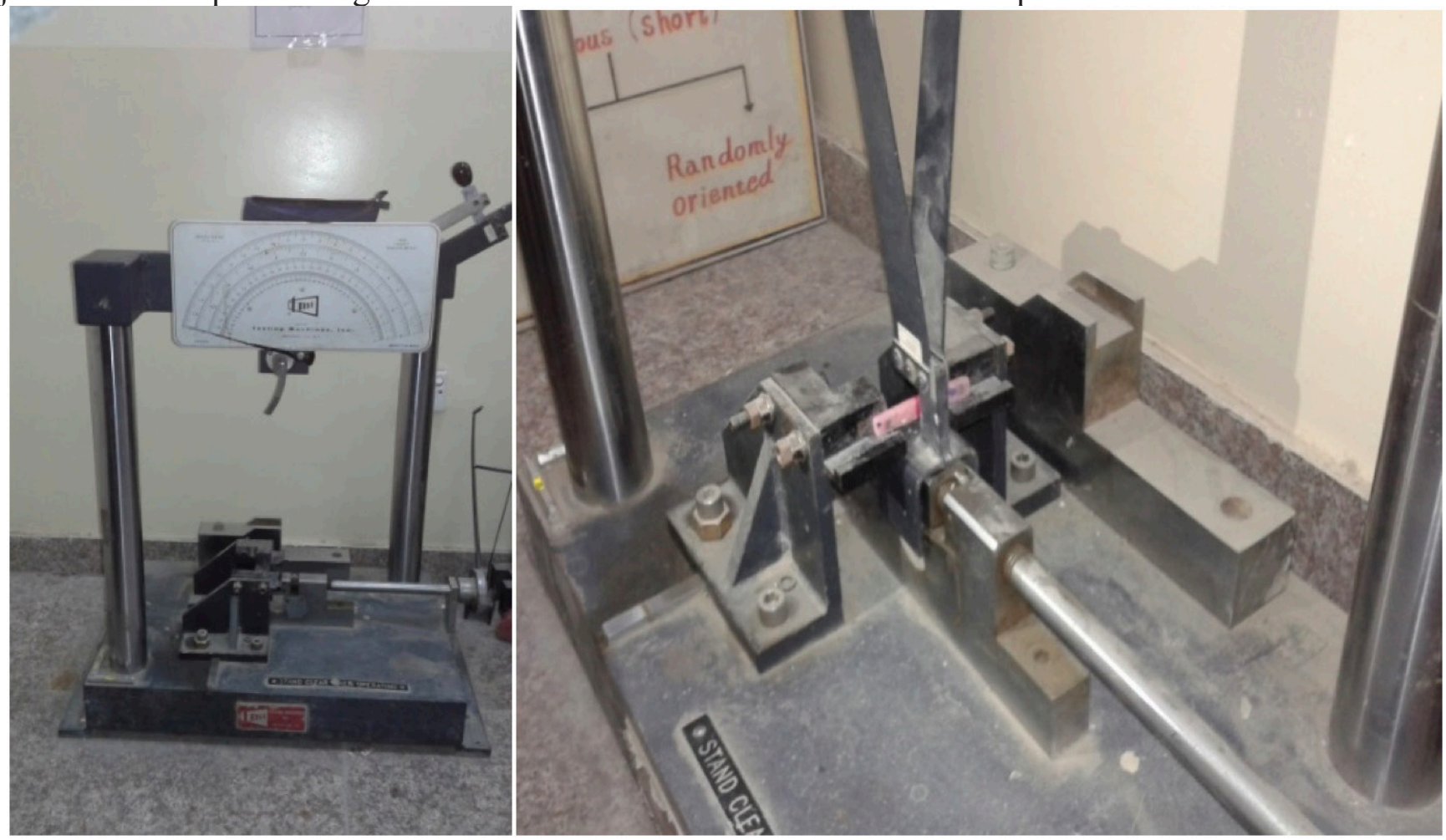

Figure 7. Impact test machine

\section{RESULTS}

\section{Samples repaired by Ivomet}

Samples data were anaylsed using SPSS v 20. in the Table 1. 
Table 1: Mean and standard deviation of all groups for Ivomet curing

\begin{tabular}{|c|}
\hline Groups \\
\hline Control \\
\hline untreated \\
\hline Monomer \\
Thiner \\
ZrO2 \\
\hline Butt joint with monomer \\
\hline Glass fiber
\end{tabular}

\begin{tabular}{|c|}
\hline Mean \pm Std. \\
\hline $11.79 \pm 0.53$ \\
\hline $11.69 \pm 0.45$ \\
\hline $11.93 \pm 0.58$ \\
\hline $9.38 \pm 0.54$ \\
\hline $9.43 \pm 0.72$ \\
\hline $22.08 \pm 0.55$ \\
\hline $19.53 \pm 0.72$ \\
\hline
\end{tabular}

\begin{tabular}{|c|c|}
\hline Min. & Max. \\
\hline 11.00 & 12.75 \\
\hline 11.00 & 12.50 \\
\hline 11.00 & 12.75 \\
\hline 8.00 & 9.75 \\
\hline 8.25 & 10.75 \\
\hline 21.25 & 22.75 \\
\hline 18.25 & 20.75 \\
\hline
\end{tabular}

As well, the Tukey test indicated that there were significant differences between 2 groups where $\mathrm{P}<0.05$ as demonstrated in Table 2. However, no significant differences were found between these groups: control and untreated, control and monomer, untreated and monomer, thinner and zirconium dioxide groups where $\mathrm{P}>0.05$. with monomer group presented the greatest value of mean impact strength. The Zirconium dioxide ( $\mathrm{ZrO} 2)$ and thiner groups had a lower mean value of impact bond strength. The glass fiber enhanced the impact strength of acrylic samples compared to other groups (untreated, monomer, ,zirconium and thiner groups).

Table 2. Tukey multiple comparison test

\begin{tabular}{|c|c|c|c|c|c|}
\hline \multicolumn{6}{|c|}{ Impact strength } \\
\hline \multirow{2}{*}{ groups } & \multirow{2}{*}{$N$} & \multicolumn{4}{|c|}{ Subset for alpha $=0.05$} \\
\hline & & 1 & 2 & 3 & 4 \\
\hline thiner & 10 & 9.3750 & & & \\
\hline $\mathrm{ZrO} 2$ & 10 & 9.4250 & & & \\
\hline Untreated & 10 & & 11.6930 & & \\
\hline Control & 10 & & 11.7880 & & \\
\hline monomer & 10 & & 11.9250 & & \\
\hline Glass fiber & 10 & & & 19.5250 & \\
\hline Butt joint & 10 & & & & 22.0750 \\
\hline Sig. & & 1.000 & .975 & 1.000 & 1.000 \\
\hline
\end{tabular}

2. Samples repaired by conventional method.

For conventional curing method, all values of mean and standard deviation are listed in the Table 3 . Table 3: Mean and standard deviation of all groups for conventional curing

\begin{tabular}{|c|c|}
\hline Groups & Mean \pm Std. \\
\hline Control & $11.88 \pm 0.62$ \\
\hline untreated & $5.88 \pm 0.45$ \\
\hline Monomer & $6.08 \pm 0.64$ \\
\hline Thiner & $4.96 \pm 0.51$ \\
\hline ZrO2 & $5.75 \pm 0.62$ \\
\hline Butt joint with monomer & $8.23 \pm 0.30$ \\
\hline Glass fiber & $7.08 \pm 0.41$ \\
\hline
\end{tabular}

\begin{tabular}{|c|c|}
\hline Min. & Max. \\
\hline 11.00 & 12.75 \\
\hline 5.25 & 6.50 \\
\hline 5.25 & 6.75 \\
\hline 4.25 & 5.75 \\
\hline 5.00 & 6.75 \\
\hline 7.75 & 8.75 \\
\hline 18.25 & 20.75 \\
\hline
\end{tabular}

The Table 3 illustrated that the greatest value of mean impact strength was with control group (11.88). On the other hand, the thiner and untreated groups had a lower value of mean impact strength. In addition, the glass fibers, butt joint, monomer and zirconium dioxide groups enhanced the impact strength of repaired acrylic. Between two groups, there were significant differences between 2 groups $(\mathrm{P}<0.05)$ as demonstrated in Tukey test (Table 4). However, no significant differences were found between these groups( untreated and zirconium dioxide; untreated and monomer; and zirconium dioxide and monomer) $(\mathrm{P}>0.05)$. 
Table 4. Tukey multiple comparison test

\begin{tabular}{|c|c|c|c|c|c|c|}
\hline \multicolumn{7}{|c|}{ Impact strength } \\
\hline \multirow{2}{*}{ groups } & \multirow{2}{*}{$N$} & \multicolumn{5}{|c|}{ Subset for alpha $=0.05$} \\
\hline & & 1 & 2 & 3 & 4 & 5 \\
\hline thiner & 10 & 4.9500 & & & & \\
\hline $\mathrm{ZrO} 2$ & 10 & & 5.7500 & & & \\
\hline untreated & 10 & & 5.8750 & & & \\
\hline monomer & 10 & & 6.1750 & & & \\
\hline Glas fiber & 10 & & & 7.0750 & & \\
\hline Butt joint & 10 & & & & 8.2250 & \\
\hline control & 10 & & & & & 11.7880 \\
\hline Sig. & & 1.000 & .473 & 1.000 & 1.000 & 1.000 \\
\hline
\end{tabular}

Comparison between two technical method

observed between the Ivomet and conventional For curing method, significant differences were methods $(\mathrm{P} \leq 0.05)$ as illustrated in the Figure 8 .

\section{Impact Strength}

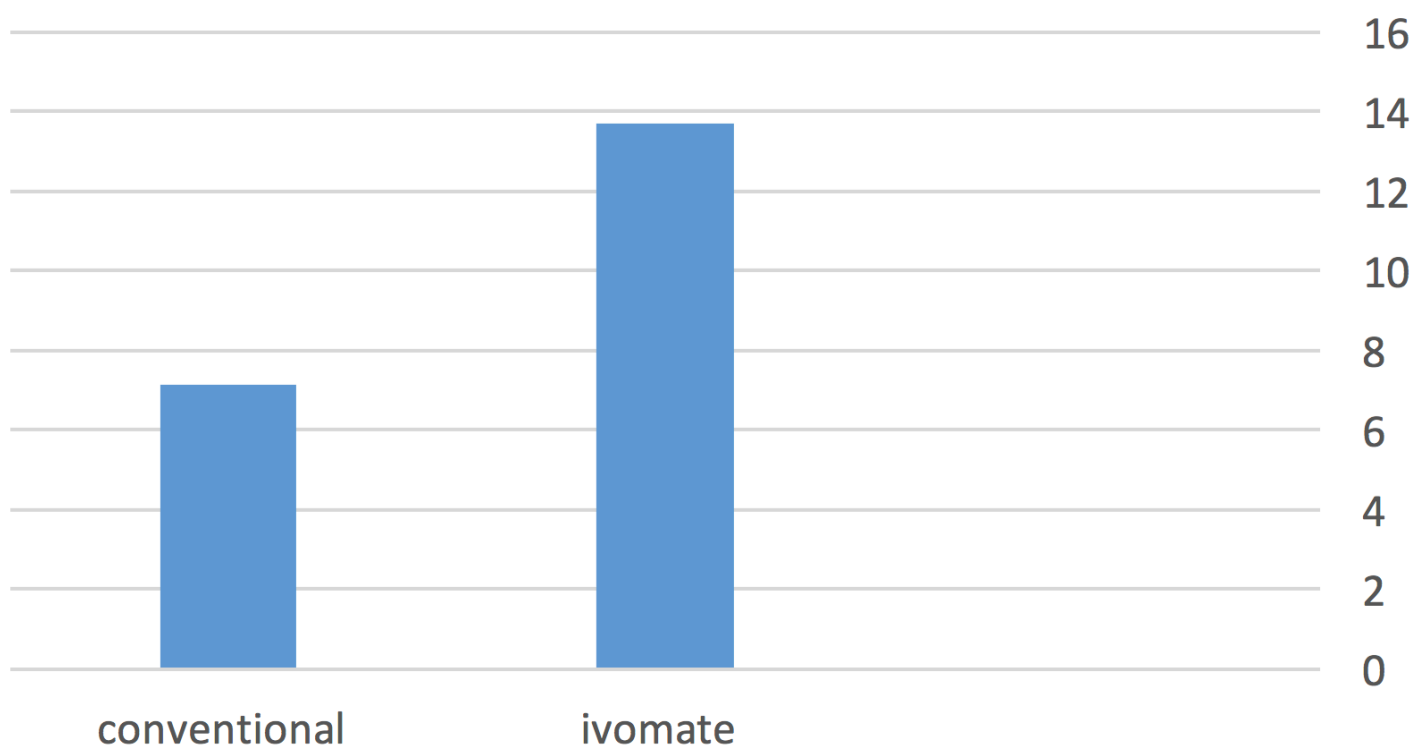

Figure 8. Bar chart of mean impact strength

\section{DISCUSSION}

In repairing procedure, all acrylic samples, which were repaired with O-cryl showed a lower mean value of impact strength when compared to specimens that were repaired with heat cured acrylic resin. The process of repairing a denture with auto cured resins have about $60-65 \%$ from the original strength ${ }^{(23)}$. The material strength, working time of the material and its dimensional stability which achieved after and during repair are the main factors which must be taken into consideration when selecting the material repair (24-25). All acrylic samples which were repaired with O-cry1 and cured by Ivomet device showed slightly a low mean value of impact strength than control group and a high mean value than the conventional method. The reason was that the auto resin was cured under pressure in water and at $40^{\circ} \mathrm{C}$. It could have improved the fracture strength of auto acrylic resin. The chemical reaction between polymer components and the monomer could be activated by heat and produced almost complete polymerization. These results are in agreement with Intisar et al , (2015) (21). The results showed a significant improvement at $(\mathrm{P}<0.05)$ in the impact strength values of all the repaired acrylic specimens treated with monomer for both the conventional and Ivomet curing techniques 
compared with control and untreated groups, this may be due because of forming interpenetrating polymer networks. These results are in accordance with Rached \& Del-BelCury (2001) ${ }^{(26)}$ and disagree with Grajower \& Goultschin (1984) ${ }^{(27)}$ as they stated that the process of wetting with monomer only did not increase the sample strength. The results showed that the lowest mean value of impact bond strength was with thiner treatment group in two technical methods. This demonstrated that some treatment solvent materials decrease the cohesion between old and new acrylic resin and led to had a lower fatigue life value ${ }^{(8)}$. This is in agreement with Jagger, R.G et al , (2002) ${ }^{(28)}$ and D.Jagger et al ,2003 ${ }^{(29)}$, where they found that monomer solvent material increase the stiffness, toughness and cohesion chemical bond of the old and new acrylic. The results showed that a lower mean value of impact strength was when using a $\mathrm{ZrO} 2$ nano filler treatment in two curing methods. The reduction in the strength could be of stress consecration around $\mathrm{ZrO} 2$ particles, which lead to crack propagation. As well, it might due to weak bond between $\mathrm{ZrO} 2$ particales and PMMA resins. The results were in agreement with the results of the study Areej and mohammed in (2016) ${ }^{(11)}$ that found the addition $\mathrm{ZrO} 2$ in acrylic repair that reduced the transverse strength of the reinforced denture. The current research indicated that the use of $\mathrm{ZrO} 2$ decreased the impact strength. These results disagree with a study which reported that the incorporation of nano- $\mathrm{ZrO} 2$ into resins improved the flexural strength of the material ${ }^{(30)}$. The impact strength was meaningfully enhanced after using glass fibers as the presence of fibers in the resin ensure transferring of load from matrix to fiber, which also eventually arrests the crack and lead to an increase in the strength of the resin and allows the resin to tolerate the force of fracture more than the samples that had no fibers ${ }^{(31)}$. In addition to above, the homogenous mixture of poly methylmethacrylate(PMMA) and fibers, good impregnation of fiber with monomer make a good contact of fiber with resin, and adequate quantity of fiber present in resin, all that caused an increase in the acrylic strength. Also, this might due to the nature of the resin and fibers which are inorganic ${ }^{(32)}$. This agreed with Ali (2005) $)^{(32)}$ and disagreed with Polyzois et al., (2001 $)^{(33)}$ who recorded a reduction in the tensile strength of the acrylic samples when reinforced with the glass fibers. These results agreed with Hanna et al., (2010) ${ }^{(20)}$ study. The butt joint group presented the highest mean value than all groups. The use of mechanical treatment (i.e. grinding with burs, airborne particle, retention grooves and sandblasting) increases the surface area, and mechanical retention to increase Vander Waal force of attraction ${ }^{(34-35)}$. As monomer is not an efficient solvent for polymethyl methacrylate, painting or immersing the surface will not adequately dislodge the debris, and create particle free surface for bonding. The treatment with chemicals, therefore, is required as metal pieces have the ability to support to acrylic materials and give higher tendency and ability with to stand the higher strength regardless the type of substances used for repair ${ }^{(36)}$. The present study was similar to a study which carried out by Golbidi and Mousavi (2010) (37). Furthermore, the results showed that all groups which were cured by ivomet device had a higher mean value of impact strength when compared with conventional method. The increase of temperature to $40^{\circ} \mathrm{C}$ had a significant impact on the mechanical properties of auto acrylic resin. However, the increase in temperature to $80^{\circ} \mathrm{C}$ had no much positive effect. Therefore, polymerization under pressure and hotwater bath leading to samples with better properties for auto acrylic resins (21). The present study concluded that the specimens which were repaired with heat-cured acrylic have a higher mean value of impact bond strength than the specimens which were repaired with O-cryl by two technical methods. The specimens, which repaired with surface treatments showed a higher bond strength except the thiner and zirconium oxide nano filler when compared with the control group by Ivomet curing . On the other hand, all surface treatments cured in conventional method showed that a lower bond strength than control group. All the specimens repaired with Ivomet curing showed a high impact strength than those cured in conventional method.

\section{REFERENCES}

1. Sarac SY., Sarac D., kulunk T., and Kulunk S. The effect of chemical surface treatments of different denture base resins on the shear bond strength of denture repair .J.Prosth. Dent.2005;94(3):259-266.

2. Raszewski Z, Nowakowska D. Mechanical properties of hot curing acrylic resin after reinforced with different kinds of fibers. Int J Biomed Mat Res. 2013;1:9-13.

3. Seó RS, Neppelenbroek KH, Filho JN. Factors affecting the strength of denture repairs. JProsthodont. 2007;16(4):30210 .

4. Naveen S Yadav, Shilpi Khare, Sunil Kumar Mishra, Rajesh Vyas, Harsh Mahajan, Rajkiran Chitumalla, Evaluation of Transverse Strength of Repaired Heat Cured Denture Base Resins without Surface Treatment and with Chemical and Mechanical Surface Treatment, Journal of International Oral Health 2015; 7(8):89-92.

5. Arioli Filho J. N., L. E. Butignon, R. D. P. Pereira, M. G. Lucas, and F. D. A. Mollo Jr., "Flexural strength of acrylic 
resin repairs processed by different methods: water bath, microwave energyand chemical polymerization," Journal of Applied Oral Science.2011; 19( 3): pp. 249-253.

6. Suvarna S., T. Chhabra, D. Raghav, D. Singh, P. Kumar, and S. Sahoo, "Residual monomer content of repair autopolymerizing resin after microwave postpolymerization treatment," European Journal of Prosthodontics.2014; 2 ( 1): pp. 28-32.

7. Stoia A.E., Sinescu C., Pielmusi M. ,Enescu M., Tudor A. , Rominu R.O. and Rominu M.” Tensile testing ,a method used to demonstrate the effect of organic solvents on acrylic teeth denture base resin bond strength" Int. J. Bio and Biom. Eng. 2011;1(5): 9-17.

8. Ibrahim, Evaluation of Fatigue and Impacted bond Strengths of Denture Base Repaired by Using Different Type of Surface Treatment, Tikrit Journal for Dental Sciences 1(2015),p: 16-18.

9. Asar N. V., H. Albayrak, T. Korkmaz, and I. Turkyilmaz, "Influence of various metal oxides on mechanical and physical properties of heat-cured polymethylmethacrylate denture base resins," Journal of Advanced Prosthodontics, vol. 5, no. 3, pp. 241-247, 2013.

10. Alhareb A. O. and Z. A. Ahmad, "Effect of A12O3/ $\mathrm{ZrO} 2$ reinforcement on the mechanical properties of PMMA denture base," Journal of Reinforced Plastics and Composites, vol. 30, no. 1, pp. 86-93, 2011

11. Areej and mohammed., 'the effect of zirconium oxide nano fillers addition of the transverse strength \& reinforcement of repaired acrylic resin"., 2016 p:40-45.

12. Polyzois G.L.; Tarantili P.A.; Frangou M.J. and Anderopoulos A.G. (2001).'Fracture force, deflection at fracture ,and toughness of repaired denture resin subjected to microwave polymerization or reinforced with wire or glass fiber “; J.Prosthet .Dent. ;86(6):613-619.

13. Stipho H. D., "Repair of acrylic resin denture base reinforced with glass fiber," The Journal of Prosthetic Dentistry, vol. 80, no. 5, pp. 546-550, 1998.

14. Nagai E., Otani K., Satoh Y. ,and Suzuki S.(2001).” Repair of denture base resin using woven metal and glass fiber : effect of methylene chloride pretreatment " J. Prosthet. Dent; 85:496-500

15. ISO 179-1:2000: Plastics Determination of Charpy impact properties Part 1: Non-instrumented impact test.

16. Barbosa D.B., Monteiro D.R., Barao V.R., Pero A.C., and Compagnoni M.A.(2008). "Effect of monomer treatment and polymerization methods on the bond strength of resin teeth to denture base material".; Gerodontology ;26:225226

17. ADA (1999):American national standers institute/ American dental association specification No.12 for denture base polymer . 10th Ed. ; Chicago :council on dental material and devices

18. Polyzois G.L.; Tarantili P.A.; Frangou M.J. and Anderopoulos A.G. (2001).’'Fracture force, deflection at fracture ,and toughness of repaired denture resin subjected to microwave polymerization or reinforced with wire or glass fiber "; J.Prosthet .Dent. ;86(6):613-619.

19. Abdul-Hadi N.F.(2007):"The effect of fiber reinforced and surface treatment on some of the mechanical properties of the repaired acrylic denture base materials (A comparative study) M.Sc. Thesis, College of Dentistry, University of Baghdad.

20. Hanna E.A. ;Shah.F.K. and Gabreel A.A.(2010)."Effect of joint surface . contours on the transverse and impact strength of denture base resin repaired by various methods .An in vitro study".6 (9):115-125.

21. Intisar J., 2015., "An Evaluation of Some Mechanical Properties of Autopolymerizing Acrylic Resin with the Modified One after Changing the Curing Environment": (In vitro Study), J. Bagh. College Dentistry.

22. AL-Shammari F ."Transverse strength measurements of repaired acrylic resin modified with different surface treatments",college of health and medical technology/ Baghdad.2014;P:41-44.

23. Naveen S Yadav, Shilpi Khare, Sunil Kumar Mishra , Rajesh Vyas, Harsh Mahajan, Rajkiran Chitumalla, Evaluation of Transverse Strength of Repaired Heat Cured Denture Base Resins without Surface Treatment and with Chemical and Mechanical Surface Treatment, Journal of International Oral Health 2015; 7(8):89-92.

24. Siddesh CS, Aras MA. In vitro evaluation of transverse strength of repaired heat cured denture base resins with and without surface chemical treatment. JIndian Prosthodont Soc 2008;8(2):87-93.

25. Seo R. S., K. H. Neppelenbroek, and J. N. A. Filho, "Factors ' affecting the strength of denture repairs: topics of interest," Journal of Prosthodontics, vol. 16, no. 4, pp. 302-310, 2007.

26. Rached RN., Del Bel Cury AA.(2001)."Heat cured acrylic resin repaired with microwave - cured one " J. Oral Rehabil; $28: 370-375$.

27. Grajower R. and Goultschin J. (1984)." The transverse strength of acrylic resin strips and of repaired acrylic samples “ J. Oral Rehabil.;(11):237-247.

28. Jagger, R.G., Jagger, S.M. Allen and A. Harrison, 2002, An investigation into the transvers and impact strength of high strength denture base acrylic resins, J. oral rehabil. 29, PP: 263-267, full text via cross ref |View record in scpus| cited by in scopus (7).

29. D.Jagger D., A. Harrison, R. Gagger and P. Miward, 2003, The Effect of Addition of Poly methyl. Methacrylate(methy 1 mthacrylat fibers on some properties of high strength heatcured acrylic resin denture base material, Journal of oral rehabilitation 30:3, 231-235.

30. Mohammed M., Ahmed , Ahmad M. and Aws S. , 2016." Influence of incorporation of $\mathrm{ZrO} 2$ nanoparticles on the repair strength of polymethyl methacrylate denture bases"International Journal of Nanomedicine.

31. Areej shihab A., the effect of fiber reinforcement on the tensile strength of repair acrylic resin cured by two different methods, the collegeof health and medical technology, 2011, p. 50-51.

32. Ali E.K. (2005): effect of fiber reinforcement on some properties The of repaired acrylic resin with different joint shape preparation, M.Sc. Thesis, College of dentistry, University of Baghdad, Iraq.

33. Polyzois G.L.; Tarantili P.A.; Frangou M.J. and Anderopoulos A.G. (2001).'Fracture force, deflection at fracture , and toughness of repaired denture resin subjected to microwave polymerization or reinforced with wire or glass fiber “; J.Prosthet .Dent. ;86(6):613-619.

34. Nagai E., Otani K., Satoh Y. ,and Suzuki S.(2001).” Repair of denture base resin using woven metal and glass fiber : effect of methylene chloride pretreatment " J. Prosthet. Dent; 85:496-500

35. George R, D'Souza M. Surface chemical treatment with 
ethylacetate and repair of fractured denture base resins: An in-vitro analysis of transverse strengths. J Indian Prosthodont Soc 2001;1:41-4.

36. Siddesh CS, Aras MA. In vitro evaluation of transverse strength of repaired heat cured denture base resins with and without surface chemical treatment. JIndian Prosthodont Soc 2008;8(2):87-93.
37. Golbidi F, Mousavi T. Transverse strength of repaired denture base material with wire and two auto polymerized acrylic resin. Journal of Dentistry, Tehran University of Medical Sciences, Tehran, Iran.2007.4(4):183-187 